\title{
ACTORES NO ESTATALES Y DESAFÍOS PARA EL DERECHO INTERNACIONAL HUMANITARIO *
}

\author{
Marco SASSÒLI \\ Catedrático de Derecho internacional público \\ Universidad de Ginebra
}

SUMARIO: 1. INTRODUCCIÓN.-2. ACTORES NO ESTATALES Y DIH.-3. ¿CÓMO VINCULA EL DIH A LOS GRUPOS ARMADOS?-4. ¿PUEDEN LOS GRUPOS ARMADOS CONTRIBUIR AL DESARROLLO DEL DIH?-5. ¿CÓMO MEJORAR EL RESPETO DEL DIH POR PARTE DE LOS GRUPOS ARMADOS?-6. OBSTÁCULOS PARA EL RESPETO DEL DIH POR PARTE DE LOS GRUPOS ARMADOS.-6.1. Reglas poco realistas.-6.2. El respeto del DIH no es recompensado.-6.3. Los esfuerzos por alcanzar compromisos con grupos armados son tachados de apoyo al terrorismo.-7. CONCLUSIÓN.

\section{INTRODUCCIÓN}

El Derecho internacional público está principalmente diseñado por y para los Estados, y sus mecanismos de implementación son una prueba fehaciente de ello. Por el contrario, la responsabilidad internacional de los actores no estatales (ANE) permanece en territorio apenas explorado y, en la mayoría de casos, no existen foros en los cuales su responsabilidad pueda ser invocada a fin de obtener los remedios correspondientes.

La realidad, no obstante, es que ONGs, compañías transnacionales y grupos armados juegan un papel creciente en la escena internacional, así sean prácticamente inexistentes para el ordenamiento jurídico internacional. Si éste último vinculara directamente a los ANE, les estaría reconociendo una cierta capacidad jurídica (con la ventaja de poder exigirles el cumplimiento de determinados estándares internacionales); en caso contrario, los estaría ignorando al dejar su entera regulación al Derecho interno del Estado territorial en el cual actúan. La segunda alternativa queda descartada respecto de grupos armados puesto que, en un conflicto armado no internacional (CANI),

* El autor agradece a la Srta. Estefanía Pólit, estudiante del Máster de Derecho de la Academia de Ginebra de Derecho internacional humanitario y derechos humanos, por haber editado de manera diligente y eficiente la versión en español de la presente contribución. 
estos se encuentran prácticamente fuera del alcance del sistema de aplicación de la ley del Estado.

\section{ACTORES NO ESTATALES Y DIH}

Los ANE han jugado siempre un papel característico en el marco del Derecho internacional humanitario (DIH); y evidencia de ello es la iniciativa de su codificación en tratados multilaterales que, desde 1859, ha estado en manos del Comité Internacional de la Cruz Roja (CICR). Cabe recalcar que, recién en el año 2015, por primera vez, dos resoluciones que impulsan un mayor desarrollo del DIH (la primera, para fortalecer la protección de personas detenidas en CANIs, y la segunda, sobre un mecanismo para incrementar su respeto) no hacen mención explícita al CICR ${ }^{1}$. De cualquier forma, las Convenciones de Ginebra de $1949^{2}$, piedra angular del DIH, consagran derechos específicos para el CICR, organismos humanitarios imparciales y otros organismos de socorro ${ }^{3}$. Tradicionalmente, los insurgentes podían beneficiarse y a la vez estar sujetos a la totalidad de las normas del DIH aplicables a los conflictos armados internacionales mediante el reconocimiento de su beligerancia por el Gobierno ${ }^{4}$. El Protocolo Adicional I de 1977 otorga a determinados ANE — movimientos de liberación nacionallos mismos derechos y obligaciones que a los Estados, bajo el DIH de los conflictos armados internacionales (CAIs) ${ }^{5}$. Considerando que en la actualidad la mayoría de los conflictos armados son de carácter no internacional, los ANE que mayor relevancia práctica revisten en el marco del DIH y que a su vez representan un punto álgido para los Estados son los grupos armados no estatales que combaten contra el Estado (o entre ellos). Las víctimas dentro de este tipo de conflictos en teoría gozan, y en la práctica precisan, de la misma protección tanto frente a grupos armados como frente a los Gobiernos.

\footnotetext{
1 Véanse Resoluciones: 1. Fortalecimiento del Derecho internacional humanitario que protege a las personas privadas de libertad (32IC/15/R1), y 2. Fortalecimiento del cumplimiento del Derecho internacional humanitario (32IC/15/R2) adoptadas el 10 de diciembre de 2015 por la XXXII Conferencia Internacional de la Cruz Roja y de la Media Luna Roja.

2 Convenio de Ginebra del 12 de agosto de 1949 para mejorar la suerte de los heridos y los enfermos de las fuerzas armadas en campaña, BOE de 23 de agosto de 1952 (Convenio I); Convenio de Ginebra del 12 de agosto de 1949 para mejorar la suerte de los heridos, enfermos y náufragos de las fuerzas armadas en el mar, BOE de 26 de agosto de 1952 (Convenio II); Convenio de Ginebra del 12 de agosto de 1949 relativo al trato de los prisioneros de guerra, BOE de 5 de septiembre de 1952 (Convenio III); Convenio de Ginebra del 12 de agosto de 1949 relativo a la protección de las personas civiles en tiempo de guerra, $B O E$ de 2 de septiembre de 1952 (Convenio IV).

3 Véanse arts. 3(2), 9 y 23 del Convenio I; 3(2) y 9 del Convenio II; 3(2), 9, 73, 75, 79, 123, 125 y 126 del Convenio III; 3(2), 9, 14, 30, 59, 61, 76, 102, 104, 109, 111, 140, 142 y 143 del Convenio IV.

4 Véase Sivakumaran, S., The Law of Non-International Armed Conflict, Oxford, OUP, 2012, pp. 9-20.

5 Véanse arts. 1(4) y 96(3) del Protocolo Adicional de 1977 a los Convenios de Ginebra del 12 de agosto de 1949 relativo a la protección de las víctimas de los conflictos armados internacionales, BOE núm. 241, de 7 de octubre de 1989 (Protocolo I).
} 


\section{3. ¿CÓMO VINCULA EL DIH A LOS GRUPOS ARMADOS?}

$\mathrm{El}$ art. 3 común a los Convenios de Ginebra deja absolutamente claro que ambos bandos en un CANI se encuentran sujetos a estas normas:

«En caso de conflicto armado que no sea de índole internacional y que surja en el territorio de una de las Altas Partes Contratantes, cada una de las Partes en conflicto tendrá la obligación de aplicar, como mínimo, las siguientes disposiciones» (cursiva añadida).

En teoría, los grupos armados se encuentran vinculados por el DIH porque los Estados así lo decidieron; porque el Estado territorial en cuestión ha legislado al respecto; o porque así lo determina el Derecho consuetudinario ${ }^{6}$. En la práctica, resulta más fácil obtener el respeto de las normas al invocar su aceptación por parte de los destinatarios y, por tanto, es preferible contar con el compromiso contraído por el grupo como tal. Así, representantes de un determinado grupo armado que han estado involucrados en las discusiones sobre su aceptación del DIH estarán más familiarizados con sus normas, percibirán el cumplimento de las mismas como un elemento importante para la credibilidad del grupo, e impulsarán a los posibles individuos recalcitrantes dentro del grupo a respetarlas.

Uno de los mecanismos para asegurar dicho compromiso se encuentra explícitamente previsto en el art. 3 común a los Convenios de Ginebra, a través del cual se alienta a las partes dentro de un CANI a «poner en vigor, mediante acuerdos especiales, la totalidad o parte de las otras disposiciones» de los Convenios. Sin embargo, y a pesar de que esta disposición enfatiza que dichos acuerdos no afectan al estatuto jurídico del grupo armado ${ }^{7}$, la mayoría de Gobiernos no están dispuestos a concluir ningún tipo de acuerdo pues temen que esto sería legitimarlos.

En cuanto a la posibilidad de que un grupo armado se obligue unilateralmente a observar las normas humanitarias, el Llamamiento de Ginebra ${ }^{8}$ es la ONG pionera en este ámbito, al haber logrado comprometer a estos actores, mediante la firma de una Escritura de Compromiso, a observar normas que comprenden desde la prohibición del uso de las minas antipersonal hasta la protección de los niños frente a los efectos de los conflictos armados y la prohibición de la violencia sexual. De hecho, el secretario general de las Naciones Unidas mencionó a esta organización como un ejemplo de éxito en el ámbito del trabajo humanitario con actores armados no estatales ${ }^{9}$.

6 Véase SASSòLI, M., «Taking Armed Groups Seriously: Ways to Improve Their Compliance with International Humanitarian Law», The Journal of International Humanitarian Legal Studies, vol. 1, 2010, núm. 5, pp. 13-14.

7 Art. 3(4) común a los Convenios de Ginebra.

8 Véase Llamamiento de Ginebra, http://www.genevacall.org/home.htm (consultada el 25 de mayo de 2016).

9 Informe del Secretario General sobre la protección de los civiles en los conflictos armados, S/2009/277, 29 de mayo de 2009, párr. 43. 
Otra forma de alcanzar estos compromisos consiste en asistir a los grupos armados a adoptar un código de conducta ${ }^{10}$. Esta regulación interna obliga a los líderes a traducir estas disposiciones legales en instrucciones comprensibles para sus miembros.

\section{4. ¿PUEDEN LOS GRUPOS ARMADOS CONTRIBUIR AL DESARROLLO DEL DIH?}

Los grupos armados deberían estar implicados en todo el proceso de desarrollo del DIH de los CANIs. Si es necesaria una revisión de este cuerpo legal, resulta lógico discutir con las partes concernidas, lo cual, en un CANI, incluye a los grupos armados. Sería absurdo sugerir que la revisión del Derecho de la guerra en el mar se realice sin consultar a la marina. El DIH debe ser aplicado por las partes en conflicto y, por tanto, debe responder a un entendimiento de sus problemas, dilemas y aspiraciones. A mi parecer, el uso y opinio iuris de los grupos armados debieran también ser tomados en cuenta al momento de evaluar el DIH consuetudinario aplicable a los CANIs ${ }^{11}$.

\section{5. ¿CÓMO MEJORAR EL RESPETO DEL DIH POR PARTE DE LOS GRUPOS ARMADOS?}

El Derecho debe ser conocido por quienes lo aplican y, en este sentido, la difusión del DIH a grupos armados debe tomar en cuenta sus particularidades. Partiendo de que un entrenamiento eficiente no se basa únicamente en el aprendizaje de las prohibiciones, sino en el entendimiento de qué situaciones de la vida real pueden ser resueltas en respeto del DIH, el riesgo de una formación realista es que aquella sea considerada como un apoyo al grupo, frecuentemente asimilada como apoyo al terrorismo. Obviamente, las dificultades que enfrentan los grupos armados para implementar el DIH difieren de aquellas que enfrenta el Estado. La idea de que estos grupos «legislen» es absolutamente rechazada por el Estado. No obstante, ¿cómo esperar que ellos, si no es en base a regulaciones de carácter general y regulaciones abstractas, aseguren la observancia del DIH por parte de sus miembros o castiguen, mediante un juicio justo, a aquellos que han violado sus normas o han cometido crímenes de guerra?

La supervisión del cumplimiento del Derecho es fundamental. Bajo el art. 3 común a los Convenios de Ginebra, el CICR u otro organismo humanitario imparcial pueden ofrecer sus servicios a grupos armados. Si el grupo

\footnotetext{
10 Para declaraciones, pronunciamientos e instrucción de actores armados no estatales en DIH, véase Geneva Call, Their Words, Directory of Armed Non-State Actor Humanitarian Commitments, http://theirwords.org/ (consultada el 25 de mayo de 2016).

11 Véase SAssòli, M., «Die Anwendbarkeit des humanitären Völkerrechts auf Aufständische und bewaffnete Gruppen: Status und Durchsetzung», en MATZ-LÜcK, N. (ed.), Der Status von Gruppen im Völkerrecht, Kiel, Duncker \& Humblot, 2016, pp. 140-142.
} 
acepta, el CICR monitorea la observancia de las normas exactamente de la misma manera en que lo hace con un Estado parte en un CAI. De manera similar, una vez que el Llamamiento de Ginebra concreta una Escritura de Compromiso, el proceso de seguimiento de la actuación de estos grupos consiste en un diálogo continuo que permite evaluar en qué medida los compromisos alcanzados se traducen en un comportamiento real en la práctica.

Finalmente, el Derecho penal internacional está dirigido de la misma manera a todos aquellos que participan en el conflicto, sea como parte del grupo armado o sea como parte de aquellos que luchan en nombre del Estado. La responsabilidad internacional de los grupos armados resulta aún más evidente frente a las sanciones implementadas en su contra por el Consejo de Seguridad. Otra área que, considero, merece una mayor indagación, es la forma en que los organismos humanitarios deberían reaccionar frente a las violaciones del DIH.

\section{OBSTÁcUlOS PARA EL RESPETO DEL DIH POR PARTE DE LOS GRUPOS ARMADOS}

Algunos grupos armados adoptan, deliberadamente, estrategias inhumanas. Otros, simplemente carecen de la estructura de autoridad necesaria para asegurar el respeto del DIH por parte de sus miembros, lo cual pone en tela de duda si efectivamente pueden considerarse como grupos armados de conformidad con el DIH ${ }^{12}$. De hecho, según varios de ellos, el DIH fue diseñado por sus adversarios, los Gobiernos. Entre otros obstáculos para el respeto del DIH, se encuentran los Estados, el ordenamiento jurídico internacional y el Derecho interno.

\subsection{Reglas poco realistas}

Algunas normas del DIH están predispuestas en contra de los grupos armados ${ }^{13}$. Otras no son realistas, pues equiparan a los grupos armados con los Estados. Por ello, es necesario verificar si, en la realidad, un grupo armado tiene la capacidad de cumplir con la norma en cuestión sin que ello implique necesariamente su derrota. Si este no es el caso, la norma simplemente no será observada, lo cual mermaría la credibilidad y el efecto protector de otras normas. La tendencia actual de los tribunales penales internacionales, el CICR, y académicos, de acercar el DIH de los CANIs a aquel de los CAIs, en particular mediante normas consuetudinarias, podría

\footnotetext{
12 Según el DIH, para que exista un CANI el grupo armado debe tener un cierto grado de organización (Tribunal Penal Internacional para la ex-Yugoslavia, asunto Fiscal c. Ramush Haradinaj y otros, caso núm. IT-04-84-T, Sentencia de primera instancia de 3 de abril de 2008, párr. 60).

${ }_{13}$ Véase $e$. g., la desigualdad en las obligaciones de los Estados y los grupos armados en los arts. 3 y 4 del Protocolo facultativo de la Convención sobre los Derechos del Niño relativo a la participación de niños en los conflictos armados, 25 de mayo 2000, BOE núm. 92, de 17 de abril de 2002.
} 
resultar en situaciones absurdas en las cuales los grupos armados estarían vinculados por normas diseñadas por los Estados para los Estados, y que únicamente ellos pueden cumplir ${ }^{14}$. La creciente integración de estándares de derechos humanos en el DIH puede desembocar en la misma situación. A modo de ejemplo, el CICR considera (especialmente en base a las prácticas de los órganos de derechos humanos) que el DIH consuetudinario prohíbe la detención arbitraria. De acuerdo al CICR, la base jurídica para el internamiento debe estar contemplada previamente en la ley, y «la persona privada de libertad [debe tener la oportunidad] de impugnar la legalidad de su detención» ${ }^{15}$. Lo anterior conlleva que los grupos armados legislen e instituyan procedimientos de habeas corpus, o que ninguna persona pueda ser detenida. ¿Es esto realista?

Una solución frente a esta falta de practicidad de ciertas normas del DIH podría ser la aplicación de las normas de acuerdo a una escala variable de obligaciones, las cuales se incrementarían de acuerdo al grado de intensidad de la violencia y el nivel de organización del grupo. El riesgo es el de comprometer el principio de igualdad entre los beligerantes contemplado en el DIH de los CANIs ${ }^{16}$. De cualquier forma, el mayor sufrimiento en los CANIs no resulta de la inobservancia de las normas que algunos actores no pueden objetivamente respetar; resulta de las violaciones, de ambos bandos, de normas que todo ser humano, en todo momento, puede respetar.

\subsection{El respeto del DIH no es recompensado}

En un CAI, un combatiente es considerado prisionero de guerra cuando cae en poder del enemigo, y es por su inmunidad que no puede ser castigado por haber eliminado a soldados enemigos. Si comete un crimen de guerra, debe ser sancionado. El interés directo en observar el DIH es evidente. En un CANI, este premio no existe. Si un ciudadano desencadena un CANI en contra del Gobierno, y mata a sus soldados, este individuo será de todas maneras procesado por asesinato una vez capturado por las fuerzas gubernamentales. Esta diferencia fundamental entre los CAIs y los CANIs es irreconciliable dentro del paradigma del Estado westfaliano. Durante el proceso de redacción del Protocolo Adicional II a los Convenios de Ginebra, los Estados rechazaron toda propuesta avanzada por el CICR en esta dirección ${ }^{17}$. Sin embargo,

14 Véase SASsòli, M., «The Convergence of the International Humanitarian Law of Non-International and of International Armed Conflicts: Dark Side of a Good Idea», en BIAGgINI, G., DigGELmanN, O. y Kaufmann, C. (eds.), Polis und Kosmopolis, Festschrift für Daniel Thürer, Zürich-Baden-Baden, DikeNomos, 2015, pp. 678-689.

15 Véase Henckaerts, J. y Doswald-Beck, L., El Derecho internacional humanitario consuetudinario, Buenos Aires, Comité Internacional de la Cruz Roja, 2007, p. 398.

16 Véase una discusión que mantuve con Yuval Shany y René Provost, "Should the obligations of States and armed groups under international humanitarian law really be equal? ", International Review of the Red Cross, vol. 93, 2011, núm. 882, pp. 425-442.

17 Véase Art. 10(5) Draft Additional Protocol II, Draft Additional Protocols to the Geneva Conventions of August 12, 1949: Commentary, ICRC, October 1973. 
se debería concebir la posibilidad de establecer incentivos —en el marco del DIH, del Derecho penal internacional y del Derecho internacional de los Refugiados- para aquellas y aquellos que observan las leyes de la guerra. En particular, los actos cometidos en un conflicto armado que no constituyen violaciones al DIH no deberían caer, bajo ningún motivo, dentro de ningún tipo de definición de terrorismo ${ }^{18}$.

\subsection{Los esfuerzos por alcanzar compromisos con grupos armados son tachados de apoyo al terrorismo}

Algunos Estados y académicos rechazan los esfuerzos por implicar a los actores armados no estatales en el respeto de las normas humanitarias internacionales argumentando que, al hacerlo, estarían incentivando y legitimando ataques contra las fuerzas gubernamentales. Cabe recalcar que el DIH aplicable a los CANIs no impide a un Estado combatir a un grupo armado, ni tampoco la criminalización de conductas en su Derecho interno, inclusive de aquellas que no constituyen violaciones del DIH. Además, los Estados han reconocido que el art. 3 común, el cual vincula a los grupos armados a observar el DIH, o el confrontarlos para que respeten sus reglas, no los legitima en forma alguna. La lucha contra el terrorismo representa un obstáculo adicional: resoluciones del Consejo de Seguridad de Naciones Unidas, legislación de la Unión Europea y ordenamientos jurídicos internos enumeran y prohíben grupos terroristas, criminalizando, asimismo, cualquier apoyo que se brinde a los mismos. El asesorar a estos grupos armados, aún a efectos de promover el respecto del DIH, es tildado de apoyo a estos grupos rebeldes. Los Estados Unidos, por ejemplo, han criminalizado cualquier apoyo brindado a los sesenta grupos que están enumerados en la lista de "terror» ${ }^{19}$, incluidos determinados grupos armados que son, de manera genuina, parte de un CANI; de hecho, consideran que la simple formación en DIH constituye «apoyo» a los grupos armados ${ }^{20}$. A mi parecer, y en cuanto a aquellos grupos rebeldes que forman propiamente parte de un conflicto armado, lo anterior constituye una violación del art. 3 común que establece que un organismo humanitario imparcial, como lo es el CICR, «puede ofrecer sus servicios a las Partes en conflicto». Lo que está explícitamente autorizado por el Derecho internacional no puede ser criminalizado bajo el Derecho interno, y las Resoluciones del Consejo de Seguridad de Naciones Unidas deben también ser interpretadas a la luz de esta disposición.

18 Véase SAssòli, M, "La définition du terrorisme et le droit international humanitaire», Revue québécoise de droit international, (hors série), Études en hommage à Katia Boustany, 2007, núm. 29, pp. 33-44.

${ }^{19}$ Lista de organizaciones terroristas extranjeras del Departamento de Estado de los Estados Unidos, http://www.state.gov/j/ct/rls/other/des/123085.htm (consultada el 26 de mayo de 2016).

${ }_{20}$ Véanse Section 2339B, title 18 of the United States Code (USC), 2339B (a)(1), Antiterrorism and Effective Death Penalty Act of 1996, y US Supreme Court in Holder v. Humanitarian Law Project, 561 U.S. 1 (2010), 130 S. Ct. 2705, 2720 and 2725. 


\section{CONCLUSIÓN}

En teoría, el DIH es pionero al abordar el rol de los ANE en el Derecho internacional. La realidad internacional, no obstante, es que los Estados son reticentes a la idea de que el CICR, actor no estatal que se encuentra fuera de su control, continúe jugando su papel tradicional en la promoción del desarrollo del DIH e, incluso a veces, que cumpla su mandato de proteger y asistir a las víctimas de todo conflicto armado. Mucho más que el CICR, los CANIs representan la mayor amenaza a la razón de ser del Estado westfaliano: el monopolio sobre el uso legítimo de la fuerza. Dichos Estados son reacios a la idea de afrontar jurídicamente a grupos beligerantes, más aún en el contexto de la lucha contra el terrorismo. Como la triste verdad de todo conflicto armado, el ignorar esta realidad no hará que ésta desaparezca. Esta actitud de negación sencillamente dejará a millones de víctimas de guerra, que se encuentran en poder de dichos grupos o bajo su amenaza, sin ninguna protección de la ley. El secretario general de la ONU acertadamente sostuvo que:

«Para evitar que los civiles sufran los efectos de las hostilidades [...], los agentes humanitarios deben mantener un diálogo coherente y sostenido con todas las partes de un conflicto, tanto estatales como no estatales. Además, aunque la cooperación con grupos armados no estatales no siempre mejorará la protección, la ausencia de una colaboración sistemática traerá aparejadas, casi con total seguridad, más, y no menos, víctimas civiles en los conflictos actuales. [...] Como mínimo, resulta crucial que los Estados miembros apoyen, o al menos no obstaculicen los esfuerzos de organizaciones humanitarias para implicar a los grupos armados a fin de mejorar la protección de los civiles, incluso en el caso de aquellos grupos proscritos por la legislación nacional» ${ }^{21}$.

Palabras clave: actores no estatales, Derecho internacional humanitario, grupos armados, implementación, Comité Internacional de la Cruz Roja.

Keywords: non-state actors, International Humanitarian Law, armed groups, implementation, International Committee of the Red Cross.

${ }^{21}$ Informe del Secretario General, op. cit., nota 9, párrs. 40 y 45. 